\title{
Drainback Solar Thermal Systems in Switzerland - Market Overview and Main Barriers
}

\author{
Sara Eicher, Mircea Bunea, Martin Guillaume, Jacques Bony and Stéphane Citherlet \\ University of Applied Sciences and Arts Western Switzerland \\ HEIG-VD, LESBAT, Yverdon-les-Bains (Switzerland)
}

\begin{abstract}
During the last years, solar thermal systems have lost in attractiveness mostly due to their high initial installation costs, higher complexity compared to photovoltaic systems and a regular need of maintenance to avoid overheating and freezing problems, e.g. control of glycol mixture properties. Drainback (DB) solar thermal systems may overcome some of these issues and contribute to the market recovery as it prevents overheating and freezing of the solar system components even when pure water is used as the heat carrier fluid. It also needs less components than classical pressurised systems, which leads to less complex, lower system costs. Nevertheless, this type of system has not been very successful in Switzerland, only accounting for a small part of the market. In order to identify the barriers preventing the wide Swiss acceptance of DB systems, a literature review was performed and an online survey conducted and addressed to the different actors of the solar thermal sector. The aim is to understand the reasons of low market penetration of DB systems in Switzerland and to clearly identify the main barriers to its spreading. Results show that investments in research, product development, technology demonstration and market deployment in the form of professional training and technology information are essential to promote the DB in Switzerland.
\end{abstract}

Keywords: solar thermal, drainback, Switzerland, barriers

\section{Introduction}

In Switzerland, solar thermal systems have lost their attractiveness because the initial investment is high and they are in competition with other renewable energy solutions. Erreur! Source du renvoi introuvable. shows the decrease in solar thermal collector sales in Switzerland over the past years. This decline in the Swiss solar thermal market is also evident in the European market, which has again declined for the eighth consecutive year (EurObserv'ER, 2017). The development of the solar thermal market is also hampered by the increased attraction of individuals and investors for photovoltaic systems.

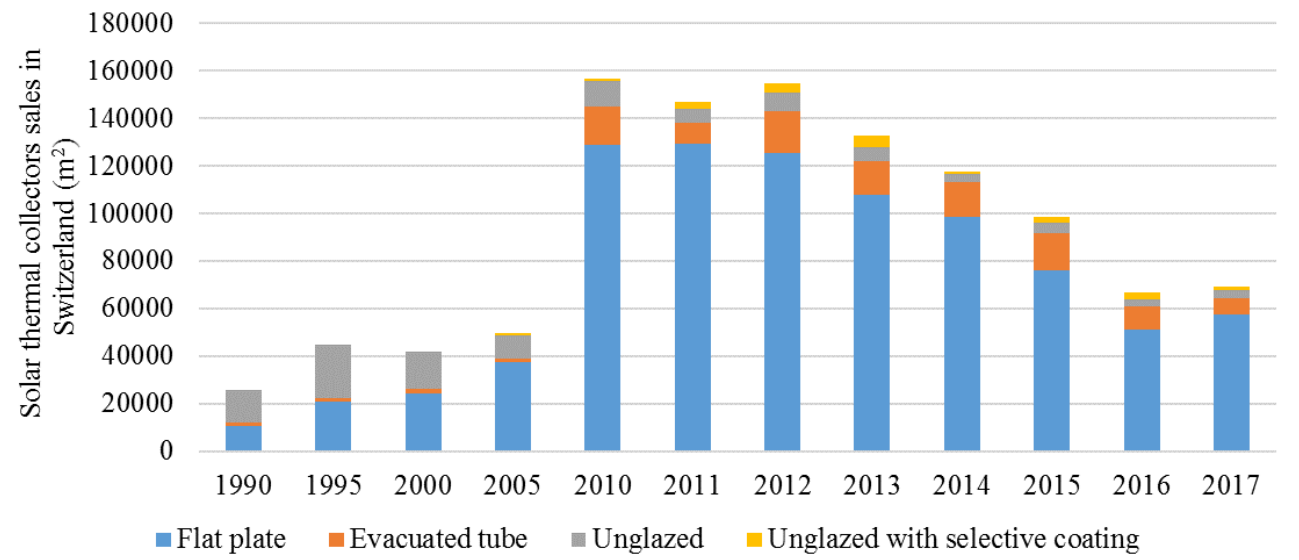

Fig. 1 Solar thermal collectors sales in Switzerland in $\mathbf{m}^{2}$ (Office fédéral de l'énergie OFEN, 2018)

Conventional solar thermal systems have been used in Switzerland for many years, mainly in the residential sector 
and mainly for domestic hot water production. The operating principle is simple: the solar energy is absorbed by the collectors installed on the roof and transported by an antifreeze mixture of water and glycol to the domestic water tank. A heat exchanger transfers the heat energy to the water in the tank. If the circulation of the heat transfer medium is interrupted, for example due to a pump failure or because the tank has reached its maximum temperature, the heat transfer medium remains in the collectors, vaporises and deteriorates over time. More frequent in summer, this phenomenon of overheating can damage the installation over time by subjecting it to extremes of expansion and contraction and technically limits the sizing of the installation to solar fractions that are not too high. The systematic degradation of the heat transfer fluid by repeated overheating of the collector also reduces its performance and weakens its antifreeze properties. These installations must therefore be subject to regular monitoring of the heat transfer fluid in order to avoid serious damage to the system due to freezing or formation of solid particles in the heat transfer fluid.

However, there is an alternative technology, historically not much used in Switzerland, in contrast to other European countries, which prevents overheating while offering freezing protection, making the solar installation more reliable, simpler and, in principle, more economical; it is the Drainback (DB) system. This paper presents the barriers that hinder the diffusion of DB systems in Switzerland and provides solutions for a better dissemination of this technology to help solar thermal professionals and ultimately the Swiss legislator to better support solar thermal energy within the Swiss 2050 Energy Strategy vision.

\section{Methodology}

The analysis of the barriers to the diffusion and the potential of DB systems in Switzerland was based on: (1) literature review and (2) online survey of 380 Swiss professionals of the solar thermal branch. The review presents the studies and developments carried out as well as the technological solutions present on the Swiss market in the field of DB systems. The questionnaire, designed to be administered over the internet, covered the following topics: current product range, Swiss DB market, feedback from experience and perception of the DB technology by solar thermal professionals. Questions were specially designed for each actor of the solar thermal sector: manufacturers/distributors, installers and planners. Thirty-one solar thermal professionals completed the survey.

\section{Literature review}

\subsection{Solar thermal in Switzerland}

Today, solar thermal energy is a technically mature technology available on the Swiss market primarily for domestic hot water production. However, it still accounts for a relatively small share of the country's total consumption (Office fédéral de l'énergie OFEN, 2018). The potential of solar heat is nevertheless high in Switzerland, and could cover a large proportion of these thermal needs, particularly in the temperature range from 10 to $60{ }^{\circ} \mathrm{C}$ (Office fédéral de l'énergie OFEN, 2016). According to the Office fédéral de l'énergie OFEN (2018): "If all existing buildings were to be optimally improved in terms of energy efficiency, it would be possible to meet the heating requirements of all Switzerland's households through the use of solar collectors".

But since 2008 the global solar thermal sector has been facing development problems and slower growth, which has not spared Switzerland. The reasons for this downward trend are the low price level of fossil fuels which affects the competitiveness of solar heat prices as well as increasing competition with technologies that are easier to install and less costly to invest. This has led industry professionals to less prescribe this type of technology causing destruturing of the sector (EurObserv'ER, 2017). At the technical level, the idea of having temperatures above $200^{\circ} \mathrm{C}$ on their roofs poses a real problem of acceptance for many people seeking solar heating technologies (Meyer, 2016).

Uncertainties regarding the energy strategy in 2016 have also contributed to a contraction of the Swiss market, but the current lack of cantonal coordination in energy policy and the expectation of appropriate implementation of subsidy policies inevitably continue to affect the dynamics of solar thermal in the residential market (Stickelberger, 2018). 
In order to reverse this trend and make solar systems more attractive in Switzerland, the market is looking to offer systems that are more reliable, simpler, less expensive and with improved performance. Research has therefore focused on these themes to offer more competitive solutions capable of reviving the Swiss solar thermal market.

\subsection{Drainback technology}

By its operating principle, DB technology offers an interesting alternative to conventional solar thermal systems. Unlike the latter, the DB allows the solar collectors to drain naturally, by gravity, into a drainage tank every time the circulation pump stops. In this way, the system is in safe mode, protected from overheating and freezing even at stand-by. Because of this drainage, it is possible to use pure water in the DB without antifreeze as heat transfer fluid. However, this unique feature of emptying and refilling the solar collectors requires a specific hydraulic design for proper operation.

This three-step operating mode: (1) filling the circuit, (2) system operation and (3) emptying the circuit has many advantages in addition to those often indicated regarding overheating and freezing. For example, without the risk of overheating, no expansion vessel or non-return valve required. Fewer components also make installation easier. As previously mentioned, another advantage is the possibility of using water instead of an antifreeze as a heat transfer fluid. Water has a better heat transfer and higher thermal capacity. Its low viscosity makes pumping easier than antifreeze mixing and requires less maintenance. However, attention must be paid to disadvantages such as the need for adequate slope of the piping and the use of appropriate components to ensure that no water will remain in the installation when the circulation pump stops. A summary of the advantages and disadvantages of DB systems can be found in (Botpaev et al., 2016).

\subsection{Classification of DB systems}

A DB system consists of three basic components: the solar collectors, the drainback vessel and the storage tank. The different types of drainback containers have made it possible in the past to establish simplified basic configurations for domestic applications. DB systems are often classified between a closed circuit and a circuit open to the atmosphere. They can also be classified according to the type of heat transfer fluid: water and antifreeze. More recently, another classification has been proposed according to the type of drainback vessel: additional drainback tank, heat storage or oversized heat exchanger, as shown in Figure 2.

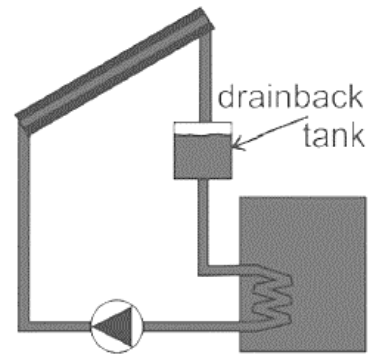

a

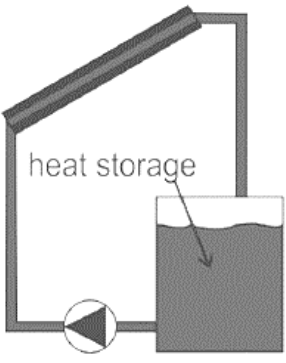

b

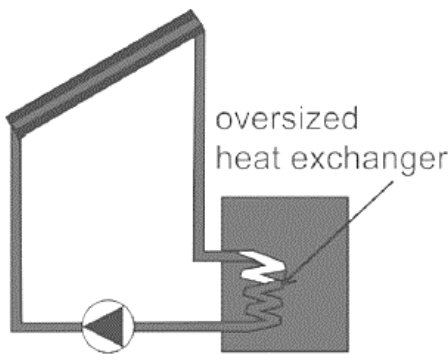

C

Fig. 1 Classification of DB systems in terms of type of drainback vessel (Botpaev, 2017)

Closed-loop, pressurized antifreeze systems with an additional drainback tank, Figure 2a, represent the current state of the art in most countries (Suter et al., 2003). For more information on the different advantages and applications of these three DB concepts, please refer to Botpaev (2017).

\subsection{Swiss $D B$ market}

Although DB systems have been used in Europe for some decades, their advantages do not seem to have convinced the Swiss market yet and only a few manufacturers offer this system at national level. A market study conducted in 2014 shows that despite dominance in some countries such as the Netherlands, Belgium and Norway (over 70\% of the market), the market share in Switzerland is estimated to be less than $10 \%$ as in other Mediterranean countries 
(Botpaev and Vajen, 2014). This same study shows that despite a large domination by German manufacturers in Europe, the DB remains almost unknown in Germany, by far the largest European solar thermal market.

While in the Netherlands the commercial success of the DB technology in the 1980s was linked to drinking water quality regulations, the major barrier in Europe seems to be the lack of qualified professionals capable of properly system installation (Suter et al., 2003). In Germany, for example, DB related failures in the past or poorer than expected performances have left some mistrust in the adoption of this technology (Berner, 2004) and today, the so-called conventional solar thermal installations are still primarily promoted. On the basis of information found on the market, three Swiss manufacturers are still offering drainback tank type of systems as in Figure 2a. Although not exhaustive, this research shows that the current offer of Swiss DB products is small and therefore not much visible.

\subsection{Research \& development}

Very few scientific studies concerning DB technology have been recorded in the public domain. The contributions encountered are mainly technology and DB market reviews (Berner, 2008, 2004; Botpaev et al., 2016; Botpaev and Vajen, 2014). The technology is often presented as safe in stand-by, frost protected, low maintenance and easy to install. The most mentioned disadvantages are the need for careful assembly, greater pumping power and the need for components that drain properly (Berner, 2007). The work carried out under Task 26 on combined systems and their findings on the state of the art of DB systems also revealed some problems for a wide dissemination of the DB in Europe. The most important is the lack of qualified professionals (Suter et al., 2003.

Combined systems using DB technology with evacuated solar collectors have been studied experimentally and by simulation. Recommendations have thus been drawn up for a correct installation of this type of system: assembly of pipes on a continuous slope; rapid filling/starting of the installation is advantageous in order to reduce pumping energy; the risk of frost formation of the external pipes is important only under certain extreme temperature conditions (Perers et al., 2014, 2015). More recently, Botpaev, (2017) conducted a series of experimental work on the fundamental principles of DB systems working with water. These results have been used to make similar recommendations regarding the operation of DB systems.

Other studies in Switzerland concern a Pilot \& Demonstration project on a solar thermal DB installation placed in a residential house (Programme P\&D, 2002). Some engineering offices and DB distributors have also provided DB integration references on their websites. For example, in Switzerland the largest installation $\left(300 \mathrm{~m}^{2}\right)$ operating on the DB principle is located in Geneva in a low income housing for hot water production, as mentioned in (cooltec.ch, 2018).

Overall, the lack of scientific publications indicates that research and development in this field is needed not only in Switzerland but also abroad. However, the few examples of DB systems in Switzerland show that the technology has an important market potential. For this, higher investments should be made and priorities set for training of professionals, the development of DB products, as well as in providing the public with more information on this type of technology. Thus, a regain in the confidence of the various players in the field: installers, planners and users, could be achieved.

\section{Survey}

This study seeks to establish the current state of the DB technology in Switzerland and to target the reasons for its low dissemination, despite its advantages. To this end, a survey on DB installations was conducted among solar thermal professionals. The survey was conducted from late April to late May 2018. More specifically, the questionnaire was designed around the following topics:

- the current product range in Switzerland ;

- $\quad$ the Swiss DB market

- feedback from experience 
- perception of the DB technology by all professionals

To reach as much Swiss professionals as possible and avoid any misunderstandings due to language barriers, the questionnaire was available in two official Swiss languages: German and French. The questionnaire was implemented in SurveyMonkey (SurveyMonkey Inc., 2018), a low cost online survey service offering easy question implementation, the ability to collect data in a consistent and quick manner and with mobile-friendly capabilities.The time required to complete this survey was approximately 10 minutes. Please refer to (Eicher et al., 2018) for the French version of the questionnaire.

Invitations to participate in the survey were sent by e-mail to nearly 380 actors involved in solar thermal energy in Switzerland, namely manufacturers, distributors, installers and engineering office, in partnership with the Swiss leading solar thermal association (Swissolar) through their extensive network of professionals. A total of 31 professionals completed the survey, 14 of whom deal currently with DB systems or dealt with it in the past.

\section{Results and Discussion}

Figure 3 provides the profile of the 31 respondents. As would be expected, installers are the best represented category. Among the 31 respondents, 14 are concerned by the DB (light colour of each category): 3 manufacturers, 1 distributor, 7 installers and 3 planners.

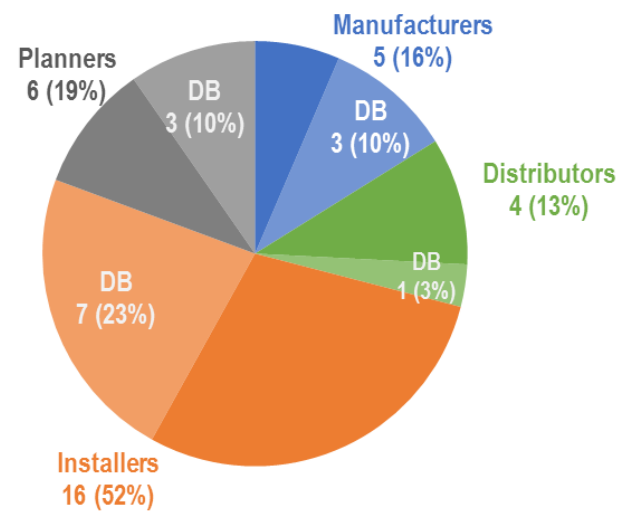

Fig. 3 Breakdown by professional category and percentage concerned by the DB (light colour)

The following three subsections present the responses only from professionals concerned by the DB. It is important to notice that for some limited cases, invalid responses were detected and not all 14 responses could be obtained. In order to clearly indicate the number of responses obtained for each question a value $n$ is provided. In multi-choice questions (indicated with MC), respondents were allowed to select one or more options from a list.

\subsection{Current product range in Switzerland}

Table 1 shows the list of DB products identified in the survey. It can be seen that five of the listed DB products fall into the additional drainback tank category (see Figure 2a), already mentioned to be the most widespread configuration. 
Tab. 1 List of DB products identified in the survey

\begin{tabular}{|c|c|c|c|}
\hline DB products & $\begin{array}{c}\text { Type of system } \\
(\text { refer to Fig.2) }\end{array}$ & $\begin{array}{c}\text { Origin } \\
(\boldsymbol{n}=\mathbf{1 0})\end{array}$ & $\begin{array}{c}\text { Heat transfer fluid } \\
(\boldsymbol{n}=\mathbf{1 2})\end{array}$ \\
\hline 1 & Drainback tank & $\mathrm{CH}$ & Water \\
\hline 2 & Drainback tank & $\mathrm{CH}$ & Glycol \\
\hline 3 & Drainback tank & $\mathrm{CH}$ & Glycol or water \\
\hline 4 & Heat storage & EU & Water \\
\hline 5 & Drainback tank & EU & Glycol \\
\hline 6 & Drainback tank & Outside EU & Glycol or water \\
\hline
\end{tabular}

In terms of product origin, 3 out of the 6 listed DB products are Swiss made. These come from the three Swiss manufacturers already identified in the literature review. The survey also shows that DB products from EU and outside EU are also available to Swiss customers. 6 out of the 10 respondents reported to use Swiss DB products.

Although DB systems can be used with water, glycol remains de most widely used heat transfer fluid, in particular by installers as shown in Fig. 44. Of the tree Swiss DB products, only one takes full advantage of using water as heat transfer carrier. This corroborates the idea that past failures related to safety and reliability of this type of technology led professionals to stay safe by prescribing glycol operating DB systems.

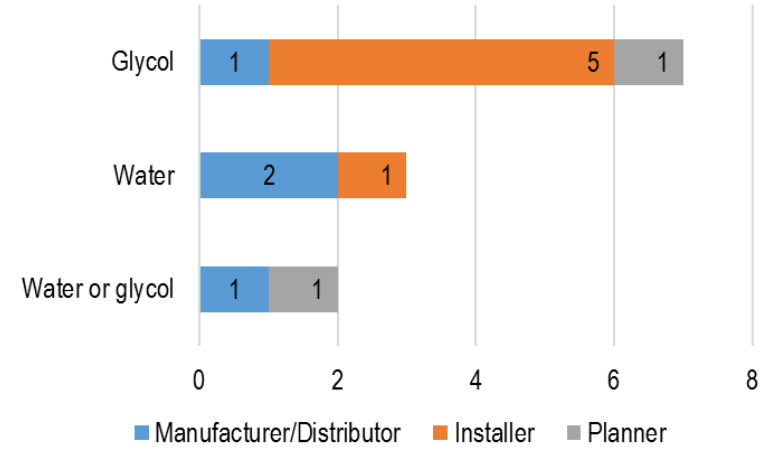

Fig. 4 Type of heat transfer fluid used in the listed DB products $(n=12)$

The top three major differences between a DB and a conventional solar thermal system are presented in Figure 5.

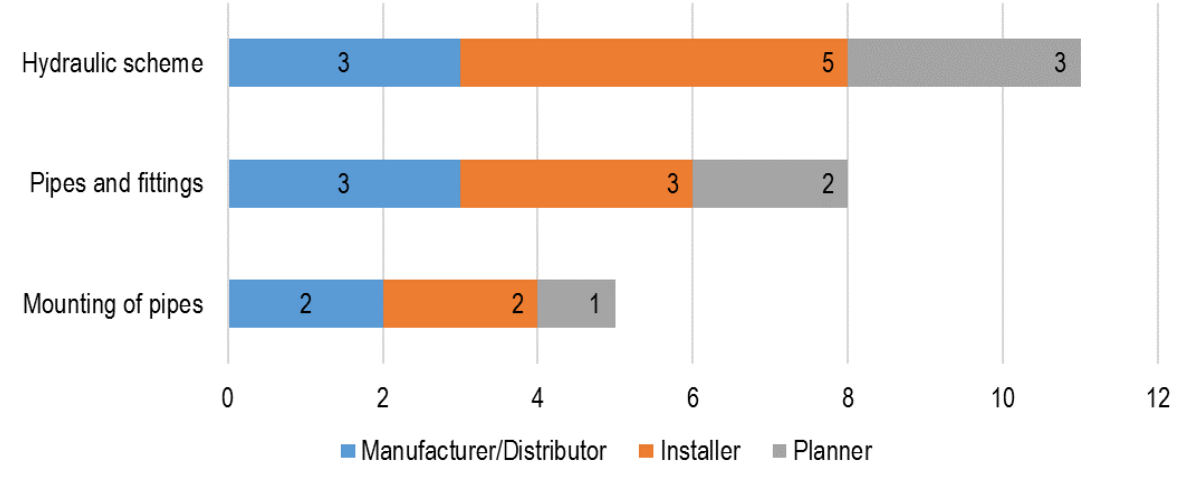

Fig. 5 Major differences between a DB and a conventional solar thermal installation (MC, $n=14)$

Due to their different operating mode, the hydraulic scheme stands out as the first major difference between these two types of systems. Some important technical aspects such as adequate pipes and fittings as well as mounting considerations, essential to guarantee complete drainage of the heat transfer carrier, follow this. These differences 
seem to indicate that professionals working with DB system are aware of the main aspects to consider for a proper DB operation.

The estimated price of a DB system is shown in Figure 6, based on the values provided by respondents. As for any type of solar thermal installation, the prices depend on: the price of the components of the installation, the number of hours required to install, the size and type of installation. The indicated values correspond to the total estimated prices of a DB facility with and without installation costs. This latter comprises only the components costs. Note that values with and without installation costs do not come from the same respondents. In addition, more prices were obtained from installers which explains the wider discrepancies between installation and components only values.

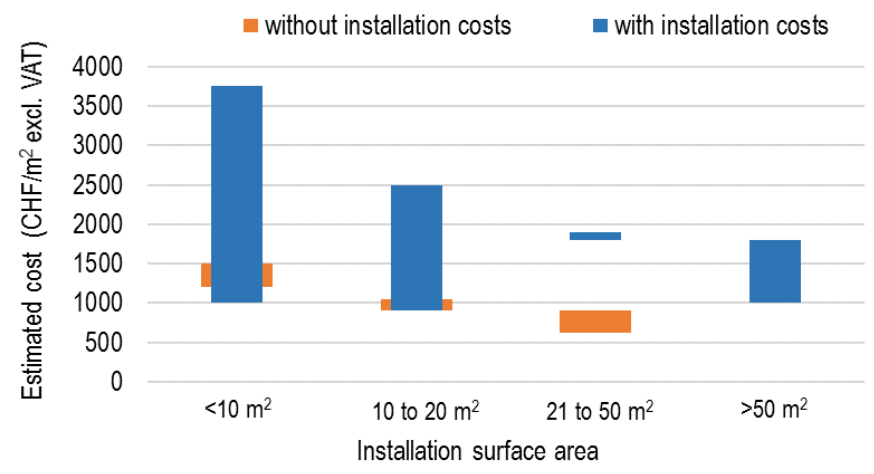

Fig. 6 Price range of a DB installation $(n=10)$

For small size installations $\left(<10 \mathrm{~m}^{2}\right)$, representing about $80 \%$ of the Swiss solar thermal installations (SHC, 2017), the price range communicated by manufacturers, on the basis of their price list, varies from 1200 to $1500 \mathrm{CHF} / \mathrm{m}^{2}$ (components only). When considering the installation costs provided by installers, these values change from 1000 to $3750 \mathrm{CHF} / \mathrm{m}^{2}$. The price per hour charged by the installer plays a role in the calculation of the latter values. It is also observed that the price decreases as the size of the installation is increased. For installations larger than 50 $\mathrm{m}^{2}$, the price ranges from 1000 to $1800 \mathrm{CHF} / \mathrm{m}^{2}$.

Pricing of solar thermal installations is, as for many other products, an important decision factor for buyers. Respondents stated that there is no difference in price between installing a DB against a conventional solar thermal system. This seems to indicate that it is not the economic factor that is preventing Swiss customers from buying DB installations.

\subsection{Swiss DB market}

Responses have shown that 10 over 14 respondents have sold/installed DB systems in the last two years. However, the sales of DB systems have remained stable or decreased in comparison to previous years, as presented in Figure 7. This result is not surprising as it follows the decreasing trend observed in the current solar thermal market.

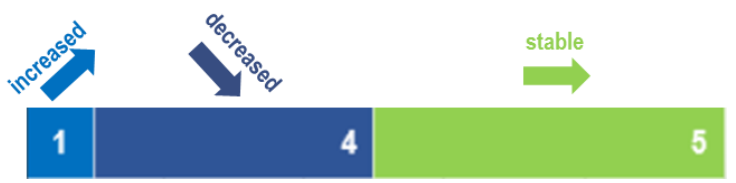

Fig. 7 Sales evolution in the last two years $(n=10)$

The size of the DB installations performed in the last two years is shown in Figure 8. It can be seen that the majority of the installations are less than $20 \mathrm{~m}^{2}$. As previously mentioned in the paper, this reflects the dominance in Switzerland, of small size solar thermal installations for single-family houses. 


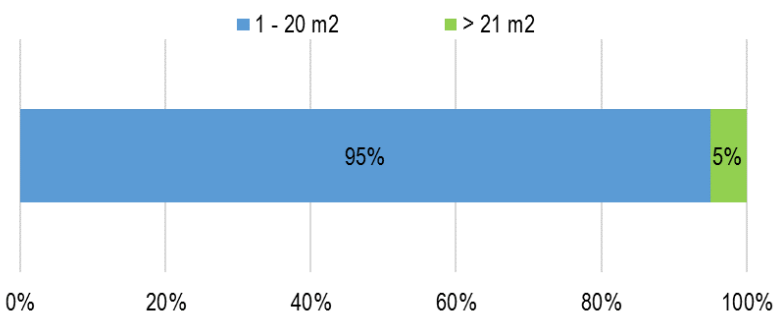

Fig. 8 Estimated percentage of small and large DB installations realised in the last two years $(n=6)$

As earlier referred in the paper, conventional solar thermal systems are primarily used for domestic hot water production. In contrast, survey results show that DB systems have been installed, on an equal basis, for both hot water production as well as for hot water coupled to space heating, see Figure 9. It is clear that by avoiding overheating, DB systems can be designed larger to achieve much larger solar fractions and consequently, cover more important heating demands. Properly installed, DB system are clearly more appropriate for combined heating demands and this advantage seems to have been considered by half of the respondents.

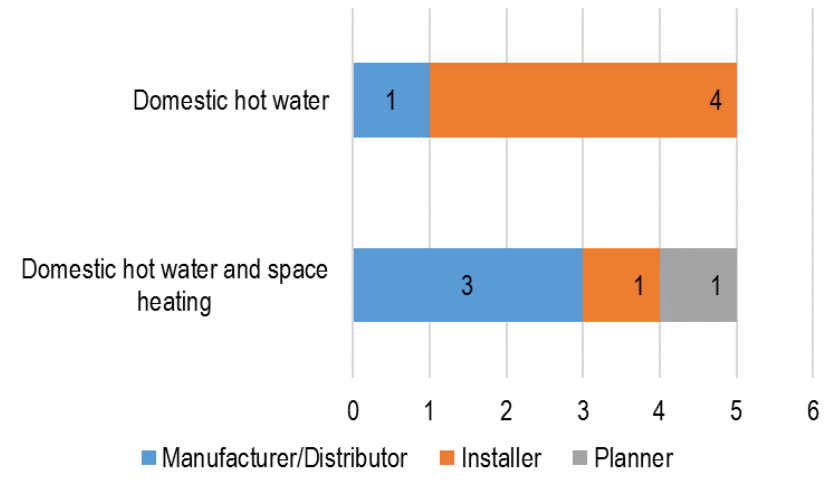

Fig. 9 Top selling applications in the last two years $(n=10)$

According to respondents, the top selling arguments for purchasing a DB installation, see Figure 10, are all related to the advantages of the system earlier mentioned in the paper. The arguments put forward by professionals clearly show a willing to present different benefits that a conventional solar thermal system is not able to provide.

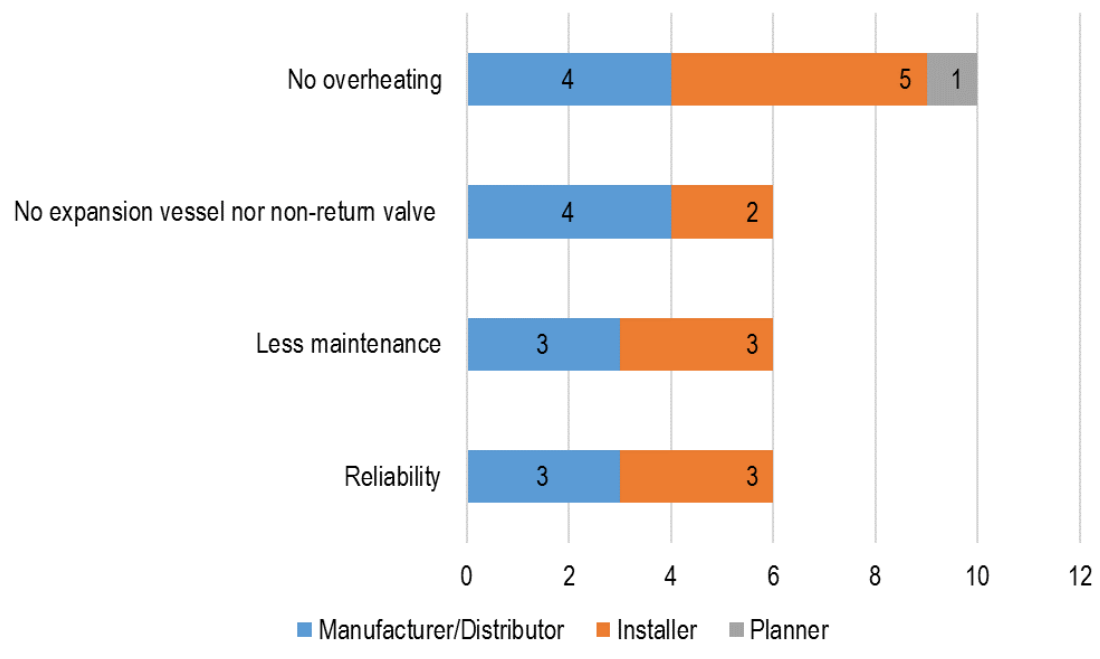

Fig. 10 Top four DB selling arguments $(M C, n=14)$

\subsection{Feedback from experience}

As previously mentioned, DB system requires special attention to mounting of pipes and choice of components to guarantee the complete drainage of the system. It has also been referred that past failures due to incorrect installation of DB system have create a profound mistrust in the technology. The need for training to regain trust in the technology is necessary and the survey shows in Figure 11 that 9 out of 14 respondents acknowledge the 
need for a specific training on DB systems. Nevertheless, only 6 out of 9 have actually followed one.

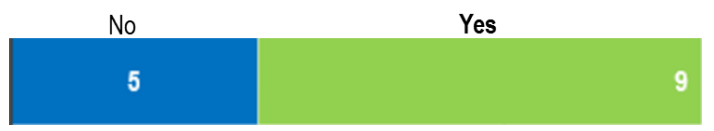

Fig. 11 Need for a specific training to install DB systems $(n=14)$

8 out of 14 respondents have not encountered any major problems with DB systems, as indicated in Figure 12.

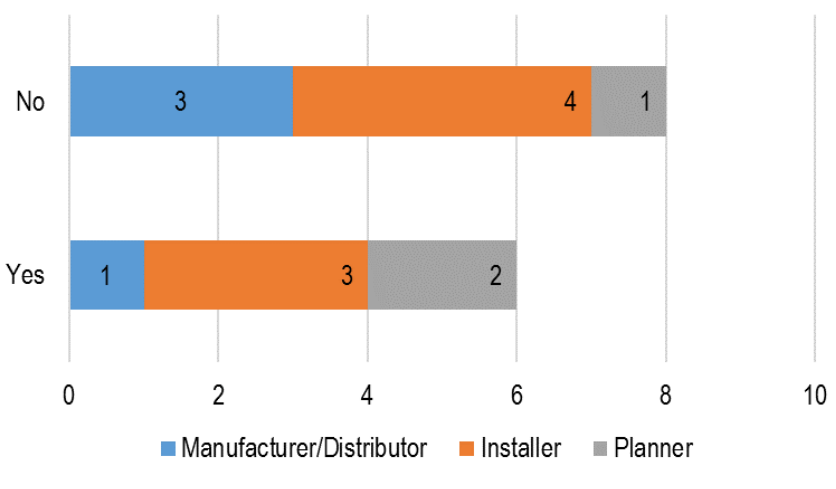

Fig. 12 Problems encountered with the DB system $(n=14)$

The main challenges encountered by respondents with DB systems are stated in Figure 13. The major challenge indicated is the mounting of pipes with the necessary slope for complete drainage of the installation. It follows pump aspects as appearing on the top two challenges. Two respondents indicated to have faced noise, freezing and control system problems of the DB installation. It is clear that training of professionals is essential to clarify technical aspects of design and installation of DB systems.

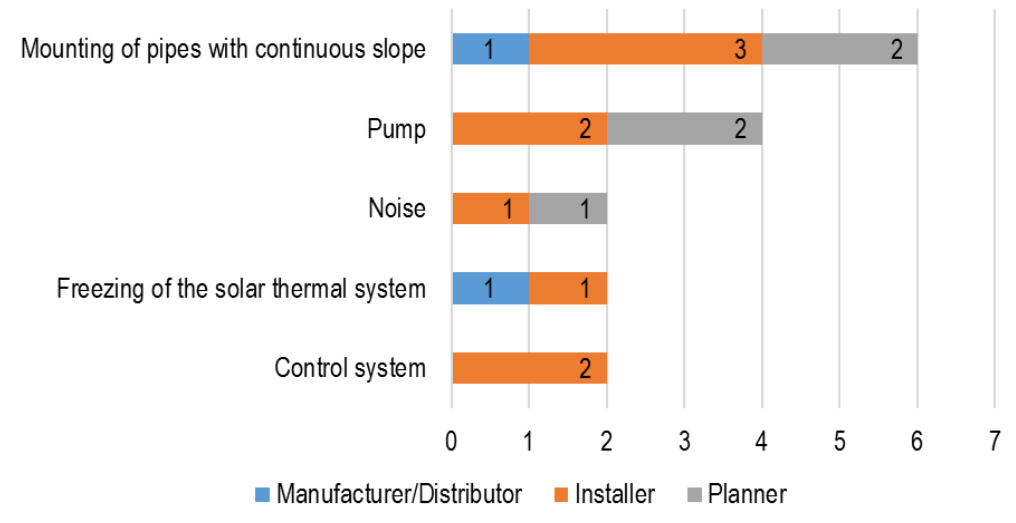

Fig. 13 Main challenges encountered with DB systems $(M C, n=14)$

\subsection{Perception of $D B$ technology by all professionals}

The changes required to promote the spreading of the DB technology in Switzerland are presented in Figure 14 and take into consideration all views from all respondents of the survey, concerned or not by the DB. As would be expected, training of professionals followed by a wider promotion and information of this type of system are seen as the main axes to explore. This would certainly result in improved reliability of the technology, also on the top four of the change factors list. 


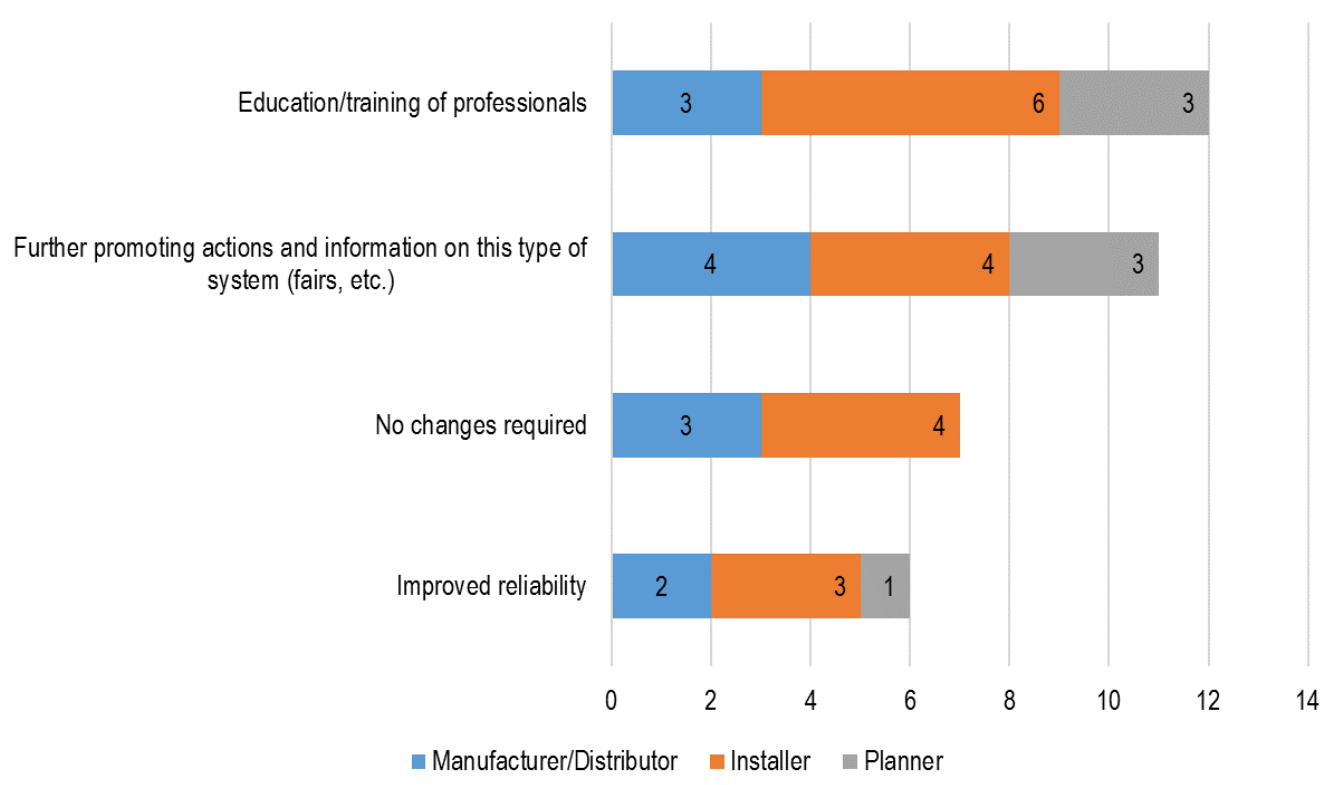

Fig. 14 Top four changes that would promote the spreading of the DB in Switzerland ( $n=31)$

\section{Conclusions}

The barriers that prevent the diffusion of DB solar thermals systems in Switzerland have been identified. The literature review highlights a lack of visibility of the technology in Switzerland and worldwide. Apart a few European countries, the market share of this type of technology remains low in Switzerland. German manufacturers are the most present on the European market but the technology remains unknown in Germany, by far the largest solar thermal market in Europe. The main reason is a mistrust in the DB technology mainly due to failures of the past often linked to the lack of qualified professionals. Current research shows a lack of scientific work in the field of DB.

The survey shows that despite available in Switzerland for more than twenty years, the DB remains almost invisible in the solar thermal market. The use of water as a heat transfer fluid is not promoted despite thermal, financial and ecological advantages. Concerns of improper installation with a potential freezing risk and its negative consequences for the installation seem to drive professionals to prescribe the use of glycol instead. DB installations were seen to have the same price as conventional installations, so the economic factor is not an issue when it comes to purchase decisions. The professionals concerned by the DB are generally satisfied with the technology but suggest that investments in the training of installers and greater information and demonstration of the technology are needed to boost confidence in the DB technology and thus promote its wider dissemination in Switzerland.

Overall, the potential of the DB in Switzerland is great. The challenge of relaunching the solar thermal market requires solutions such as DB but it is clear that investments in research, product development, technology demonstration and market deployment in the form of professional training and technology information are essential.

\section{References}

Berner, J., 2004. Drain Back for export. Sun \& Wind 2, 32-37.

Berner, J., 2007. Drain back: full protection with empty collectors. Sun \& Wind 1, 60-65.

Berner, J., 2008. Drainback systems : empty and safe. Sun \& Wind 5, 48-53.

Botpaev, R., 2017. Experimental investigations of water filled drainback systems, PhD Thesis, Uni-Kassel. 
Botpaev, R., Vajen, K., 2014. Drainback Systems : Market Overview, in: Gleisdorf 2014.

Botpaev, R., Louvet, Y., Perers, B., Furbo, S., Vajen, K., 2016. Drainback solar thermal systems : A review. Sol. Energy 128, 41-60.

Cooltec, URL cooltec.ch (access July 2018).

Eicher, S., Bunea, M., Bony, J., Guillaume, M. and Citherlet, S., DrainBiS - Drainback in Stwizerland. Final report 2018. SuisseEnergie.

EurObserv'ER, 2017. État des énergies renouvelables en Europe.

Meyer, J.-P., 2016. Pushing down stagnation temperature. Sun \& Wind 6, 16-19.

Office fédéral de l'énergie OFEN - Energie solaire, URL bfe.admin.ch (access July 2018).

Office fédéral de l'énergie OFEN, 2016. Plan directeur de la recherche énergétique 2013-2016.

Office fédéral de l'énergie OFEN, 2018. Le recensement du marché de l'énergie solaire en 2017.

Perers, B., Furbo, S., Fan, J., Kong, W., Chen, Z., 2014. Drain Back, Low Flow Solar Combi Systems: Design , Monitoring and Simulation, in: EuroSun 2014 - International Solar Energy Society.

Perers, B., Furbo, S., Fan, J., Kong, W., Chen, Z., 2015. Drain back systems in laboratory and in practice. Energy Procedia 70, 300-310.

Programme P\&D domaine solaire actif: AccaDueO: Installation solaire sans antigel, 2002.

SHC, Status of the market for solar thermal systems - Switzerland. Country report 2017.

Stickelberger, D., Evolution du marché de l'énergie solaire boom mondial, stagnation en Suisse, URL swissolar.ch (access July 2018).

Suter, J-M, Kovács, P., Hausner, R., Visser, H. and Peter, M., 2003. Durability and reliability of solar combisystems, in: Weiss W. (Eds) Solar Heating Systems for Houses - A Design Handbook for Solar Combisystems. James \& James Ltd., London, pp. 182-190.

SurveyMonkey Inc, URL surveymonkey.com (access July 2018). 